\title{
Entre la academia y el aula: La aparición de actores marginados en la Historia y su enseñanza
}

\author{
Sixtina Pinochet Pinochet ${ }^{1}$ \\ Néstor Urrutia Muñoz ${ }^{2}$
}

Recibido: 10 de marzo de 2016 Aceptado 15 de abril de 2016

\begin{abstract}
Resumen
Indudablemente, la historia tradicionalmente se ha construido desde la verticalidad: mientras que algunos son los grandes protagonistas, otros quedan marginados del análisis del pasado. Sin embargo, a la luz de los cambios dentro de la disciplina de la segunda mitad del siglo XX, se hizo patente la necesidad de aproximarse a aquellos actores históricamente marginados. El presente trabajo busca exponer el trato que se ha hecho de algunos de estos colectivos apartados en dos planos: la disciplina historiográfica (antes y ahora) y el currículo de enseñanza actual, de tal manera de poder apreciar cuál es la forma en la que son presentados y bajo qué parámetros.
\end{abstract}

Palabras clave: marginados, historiografía, currículo, enseñanza de la historia

\section{Between the academia and the classroom: The emergence of marginalized actors in history and their teachings}

\begin{abstract}
Undoubtedly, history has traditionally been built from the verticality; some have a leading role while others are excluded from the analysis of the past. However, in light of changes within the discipline of the second half of the Twentieth Century, the need to approach those historically marginalized actors became evident. This paper seeks to expose the treatment given to some of these collectives on two levels: the historiographical discipline (then and now) and the current teaching curriculum, in order to appreciate what is the way they are presented and under what parameters.
\end{abstract}

Keywords: marginalized, historiography, curriculum, history teaching

Chilena. Doctora en Didáctica de las Ciencias Sociales por la Universidad Autónoma de Barcelona. Académica de la Universidad Católica del Norte. E-mail: profesorasixtina@gmail.com

2 Chileno. Doctor en Culturas en Contacto en el Mediterráneo por la Universidad Autónoma de Barcelona. Académico de la Universidad Alberto Hurtado. E-mail: nestor.urrutia@gmail.com 


\title{
Entre a acadêmia e a sala de aula: 0 surgimento de atores marginalizados na história e seu ensino
}

\begin{abstract}
Resumo
Sem dúvida, a história tem sido tradicionalmente construída a partir da verticalidade, enquanto alguns são os grandes protagonistas, outros são excluídos da análise do passado. No entanto, à luz das mudanças dentro da disciplina da segunda metade do século XX, tornou-se evidente a necessidade de se aproximar a esses atores historicamente marginalizados. Este trabalho procura expor o trato que se tem feito de alguns destes coletivos diferenciados em dois níveis: a disciplina historiográfica (então e agora) e o currículo do ensino atual, com a finalidade de apreciar qual é a forma em que são apresentados e sobe que parâmetros.
\end{abstract}

Palavras-chave: marginalizados, historiografia, currículo, ensino da história.

Fukuyama arroja una afirmación tajante hacia finales del siglo XX, diagnosticando para el devenir humano una sentencia clave que nos ayuda a comprender la historiografía que prevaleció hasta la primera mitad de esa centuria: existen personas que se distinguen como más y menos importantes al momento de abordar el pasado (1992). No estamos hablando de nada nuevo. Se trata de un modelo que ha sido ampliamente reproducido por los Estados modernos a fin de reafirmar sus propios presentes; se busca entonces en la historia a un soporte. Por lo mismo, al momento de abordar el pasado se torna indispensable resaltar a aquellos individuos que simbolizan los valores que se anhela destacar desde una mirada oficial; en general los mismos cumplen una tríada fundamental: hombres, adultos y pertenecientes a instituciones que los avalen. De esta manera, las filas se van cerrando y las miradas del colectivo que revisa la historia se posicionan hacia un mismo horizonte, distinguiendo a los grandes hombres y sus grandes acciones.

Lo dicho con anterioridad tiene una consecuencia igualmente importante. Al ser guiados los razonamientos hacia el pasado comprendiendo únicamente unos cuantos privilegiados como sus protagonistas, las voces del resto de los individuos se pierden en silencios intencionados. Finalmente, el estudiar a unos apunta a una labor ordenada, mientras que reconocer las distintas aristas del colectivo conllevaría al caos y, además de eso, se caería en lo irrelevante. El sistema sobre el cual se edificó esta forma de concebir el devenir humano, el positivismo, apelaba precisamente a ello, a que la historia debía construirse desde una mirada única, que apuntara a la verdad objetiva (así, en singular) y que se interesara por lo realmente importante, lo que se traducía en lo político mayormente. Y es que controlar la historia significa además ratificar la construcción de un modelo, como anuncia Koselleck (1993; p. 338 - 339); se trata de tomar las experiencias 
de los tiempos pretéritos para construir un horizonte de expectativas. La lógica entonces apuesta a que otros actores de la historia, los secundarios, queden al margen de los libros, para leer únicamente sobre aquellos cuya visión es funcional para las naciones. El mismo principio, podríamos decirlo así, funciona para todos los textos de este carácter, desde los académicos hasta los pedagógicos, al menos hasta la primera mitad del siglo XX. Sólo daremos un ejemplo para graficar esta situación: el máximo exponente de la corriente positivista en Chile, Diego Barros Arana, presenta una obra magna que comprende entonces un trabajo cuidadoso, siguiendo todos los principios del paradigma, esto es, ceñirse a las fuentes oficiales, realizar una labor de trasvasije de información y resaltar, por supuesto, a los grandes hombres que construyeron la nación. Pero evidentemente, no se trata de los únicos actores dentro del pasado; para resaltar la importancia de su obra y de sus puntos fuertes, en algunas ocasiones menciona a los otros, los que denominaremos marginados. Por ejemplo, para hacer ver cómo se vivía en la Araucanía y cuál era la organización de los conglomerados nativos, menciona que se trata de una forma de vida completamente ajena a todo canon, para recalcar lo mismo coloca como ejemplo que las mujeres son las que trabajan y los niños son propensos a estar borrachos (2000; 66). La sentencia de Barros Arana es concordante con lo que ya hemos dicho, su juicio en pleno siglo XIX es una mirada orientada a desestimar lo que él denomina como salvaje, en beneficio por supuesto de la conformación y extensión del naciente Estado chileno. Siguiendo la frase inicial, unos se creen superiores y buscan materializarlo; la historia es una buena herramienta para hacerlo.

A pesar de todo lo anteriormente señalado, es evidente que ya no vivimos en esa realidad académica. Particularmente hacia mediados del siglo XX y siguiendo las direcciones que provenían desde la escuela francesa de Annales, en su mayoría, la historiografía cambió de paradigma. La nueva corriente buscaba subscribirse a la tesis arrojada por uno de sus mentores, Fernand Braudel, quien apelaba a conseguir una historia total (Burke, 1999: 44). La idea entonces era reformular la disciplina de tal manera de hacerse cargo de las distintas partes del todo que es el pasado. La tarea era entonces titánica, todos aquellos que durante siglos fueron los marginados, ahora debían incluirse por lo que la misma actividad debió modificar sus bases y apelar a cuestiones como nuevas fuentes validadas o nuevos enfoques interdisciplinarios. Para la realidad chilena, el discurso vino a tener un eco posterior, algo tardío, respondiendo a las realidades políticas propias del tenso clima de la guerra fría, con honrosas excepciones. Entendido que el peso de un pasado como el anunciado caló profundamente dentro del desarrollo de la historiografía, es que llegamos entonces a una pregunta necesaria: ¿de qué manera se alteró entonces la tarea de abordar a los colectivos marginados dentro de la historia?, ¿en qué formas se concretó? 


\section{Una revisión contrastada sobre actores marginados en la disciplina}

Responder a dichas interrogantes pasa por un ejercicio amplio: por ejemplo, hay que distinguir quiénes son estos actores marginados. Para el caso de este trabajo, hemos determinado que los mismos se reduzcan a tres grandes grupos: nativos, mujeres, niños y niñas. De esta manera, nos tomamos precisamente de los secundarios que distingue Barros Arana en un sentido anecdótico. Además de eso, nuestro ejercicio pasará entonces por analizar dos niveles: el primero buscará contrastar las corrientes historiográficas de cara al cambio de paradigma, viendo así cómo los focos de atención han ido cambiando y cuáles han sido las reales técnicas de reposicionamiento de los actores referidos, en algunos actores que se tomarán como ejemplos emblemáticos dada su mirada historiográfica y su tiempo. Por otra parte, es indispensable que abordemos los libros de texto escolar para ver si las aproximaciones hacia estos actores han tenido alguna repercusión en la formación de los estudiantes. Esto porque si existe la modificación que creemos, al menos en ciertos planos de la disciplina, (pensamos) debería tener algún tipo de repercusión en la asimilación que realiza la oficialidad institucional acerca de los marginados. Comencemos entonces por realizar el ejercicio desde la historiografía.

En un análisis acerca de qué significaba construir la memoria, Isabel Piper señala que pasa por un ejercicio de domesticación del pasado para hacerla funcional a ciertos fines (2000: 97). Esta palabra en particular es muy importante al momento de abordar la realidad dentro de la historiografía de los aborígenes chilenos. José Bengoa señala que dentro del contacto entre los nativos locales y los colonizadores europeos, la máxima fue una, inequívoca: domesticarlos, para hacerlos entonces útiles a sus propósitos (2004: 30). La idea es concordante y puede mirarse en varios planos, pero lo realmente importante es que de esta manera, algunos miembros de nuestro pasado se quedaron silenciados en la historia, reducidos a su aspecto operativo. Nuestras historias generales entonces estaban desmembradas. Y es que, en términos prácticos, la voz de los nativos se intentó apagar rápidamente desde los primeros años de la conquista en adelante, y decimos esto porque en efecto se trata de una cuestión literal, de ahí por ejemplo que lenguas como el selk'nam ya no pueda ser escuchada en nuestros días. Evidentemente el brazo colonizador intentó imponer otra clase de lógicas de comunicación que terminaron por hacer desaparecer algunos de los idiomas nativos. Con ellos se fue gran parte del legado histórico que, hasta ese momento, se transmitía bajo un régimen de transmisión oral y, dadas sus especificidades, no pudo llegar a la actualidad. Pero, como hemos señalado con anterioridad, este colectivo nunca estuvo del todo ausente de las producciones historiográficas que comprendían la conformación de la nación chilena, esto debido al contrapunto que suponía dentro del proceso de civilización que estaba experimentando el país. Domingo Amunátegui publica dos libros 
en donde precisamente hace ver cómo se daba dicha relación, en su famosa memoria a propósito de las encomiendas (1909: 352), el autor hace ver que las mismas fueron un mecanismo de acercamiento por parte de los colonizadores hispanos hacia los nativos chilenos. De esta manera lo que habrían buscado era mantenerlos bajo su protección y crear lazos afectivos, constituyendo uno de los ejes claves para comprender la conformación de la sociedad chilena. El resultado es bastante claro: por una parte se entiende que la entidad externa es mejor, por lo mismo debe estar a la cabeza incluso sin siquiera conocer el territorio al que arriba, mientras el componente nativo debería someterse a este parámetro impuesto toda vez que su condición es naturalmente inferior, y es necesario que lo haga porque, finalmente, no existe otra alternativa. Lo cierto es que este tipo de situaciones hacen comprender, entre otras cosas, que la alteridad es lo que marca la relación desde un inicio con los nativos nada nuevo bajo el sol-, toda vez que hoy se continúa prácticamente la misma variante, haciendo comprender que los nativos son otros y no necesariamente como parte de la nación. De hecho, muchas veces son históricamente excluidos del devenir histórico y su participación sólo se vuelve a retomar en tanto cuento tiene alguna injerencia con la conformación de la nación chilena. Mansoulet no puede ser más explícito en esta apreciación; en su texto de la crónica de la frontera en Chile señala que existe una sentencia a partir de 1892, en donde la Araucanía pasó a ser oficialmente territorio chileno. De esta forma, ocurre lo realmente importante para ellos; las tierras del sur de Chile pasaron a formar parte de la república. En su diagnóstico, los nativos, en condición de salvajes, tenían desaprovechados estos territorios y no fue sino hasta la conformación de la Sociedad Nacional de Agricultura que se pudo establecer un orden en una zona que históricamente estaba en el caos (1893: 16-17). El punto de vista del nativo a propósito de estos fenómenos, como es lógico, jamás se tomó en consideración. La sentencia es clara, las tierras de Chile no pueden estar en posesión de sus habitantes originales, por lo mismo, todo lo que diga relación con el pasado debe hablarnos de ellos como entidades negativas y que incluso ellos mismos se aprecien como tales. Este es el fenómeno que José Bengoa calificó de "asimilación forzosa" (2004: 21). Es este mismo historiador quien, de alguna manera, ha intentado tomar la bandera de lucha y cambiar la cara acerca de la concepción que se tiene de los nativos dentro de la historiografía chilena. Bengoa señala que la demonización del componente nativo, de alguna manera, ha triunfado en el discurso imperante en Chile, lo que resulta evidente si tenemos en consideración que hoy, incluso, se califica a este colectivo como uno altamente peligroso, del cual hay que hacerse cargo. Su análisis, que es transversal, lo ha llevado a entender que las realidades de aculturación en las distintas zonas se han materializado en políticas violentas. Jorge Pinto, a propósito de sus estudios sobre las fronteras mapuches, ha señalado un hecho fundamental que nos habla del protagonismo solapado que han poseído los elementos nativos de Chile; es lo que ha ocurrido en territorio araucano, donde el pensamiento oficial nunca ha conseguido realmente el cometido 
de la asimilación de su ideología; por lo mismo, el discurso a propósito de la rebeldía se ha ido alimentando con el paso del tiempo (2003: 253). Todo ello daría cuenta de un colectivo que se ha intentado marginar desde la historiografía oficial, pero que no ha podido ser acallado. El experimento de Escucha Winca, texto a cargo de cuatro historiadores de origen mapuche (Marimán, Caniuqueo, Millalén y Levil) es una muestra de ello y de cómo existe una visión propia al otro lado de la frontera, otorgando el contra-discurso necesario para comprender que ahí existe otra voz, una esperando ser oída (2006).

En relación a otro colectivo opacado, las mujeres, hemos de decir que su presencia en la historia es mucho más evidente de forma intencionada, toda vez que no se puede negar su presencia en el mundo: de alguna mujer tendrán que nacer los héroes y enamorarse de alguna para poder entonces dar cuenta de su virilidad y mantenerse acordes al paradigma romántico del siglo XIX, en comparación con ellas, vistas como suaves elementos de la sociedad. Por lo tanto, las mujeres, hasta esta misma centuria, se entienden como anexadas a alguna presencia masculina ilustre. Emblemáticos son los casos de Javiera Carrera o Isabel Riquelme. La mujer era decorativa. A inicios del siglo XX, José Bernardo Suárez escribe una obra biográfica con la presentación de mujeres importantes en el caso americano; recorriendo todo el mapa continental destaca figuras como Luisa Recabarren y Antonia Salas de Errázuriz, ambas a pesar de ser mujeres destacadas, parecen ser puestas en este texto toda vez que son la antonomasia de la mujer que se esperaba en su tiempo, esto es: que acompañe a su esposo y destaque en valores altamente apreciados como la solidaridad. Suárez es un ejemplo de esta mirada vertical hacia el género femenino, sin embargo, destaca a la autora Rosario Orrego como una de las mujeres con la pluma más reconocida de su tiempo (Suárez, 1909: 148-150). Era un valor que no era tan reconocido para el caso de las mujeres, y, también hay que señalarlo, era una representante del género literario con acercamientos al feminismo más tradicional, ¿acaso Suárez valoró también a este movimiento? En el afán por la normalización de un nuevo Estado en Chile, la mujer debía cumplir un rol importante, ser el apoyo de los varones. Concretamente esto se traduce en que debe ser una mujer sumisa, entregada a los quehaceres domésticos y básicamente, fértil para que el nombre del varón -y no el propio- se conserve en el paso del tiempo. En los planos historiográficos únicamente destacan aquellas que tienen proximidad con alguna figura de poder, poseen alguna cualidad o virtud a ser resaltada o bien, por ser entidades perversas, como es el caso de la Quintrala en la obra de Vicuña Mackenna (1887: 132). En ningún momento los autores del siglo XIX nos hablan de la importancia de su rol en el espacio privado, de sus aspiraciones, de las mujeres trabajadoras o de colectivos de mujeres-. Todas ellas destacan exclusivamente en los planos individuales, como arquetipos. Es entonces que hay que señalar que los primeros intentos por rescatar la historia de las mujeres desde una perspectiva que se escapara 
del rol tradicional serían altamente rupturistas. En este sentido, Diana Veneros es una de las primeras representantes dentro del país que intentó dar voz a las mujeres históricamente silenciadas. En su texto Perfiles Revelados presenta efectivamente el concepto de género como una variante para comprender la historia de un colectivo que ha sido desplazado por la cultura occidental (1997). De su mano, historiadoras se atrevieron a mostrar cómo sí existían organizaciones femeninas y representantes que buscaban transgredir estos roles de género cerrados por distintos motivos (incursión en la educación, el mundo laboral o la política). Ejemplos más recientes como el de María Angélica Illanes con las visitadoras sociales (2006: 229) y María Soledad Zárate con el caso de las matronas/obstetras (2007: 268), nos dan cuenta de que, en ciertas oportunidades de nuestra historia local, las mujeres han resultado claves para las entidades oficiales $y$, desde ahí, han tenido una plataforma para evidenciar dentro de sus campos de acción un diagnóstico de la realidad nacional que realizan desde sí mismas, comprendiendo que se empoderan en su formación, el trabajo y su importancia a nivel público. Llegados a este punto es posible decir que, es posible reconocer en nuestro devenir un hecho fundamental que intentó ser tapado sin ningún sentido: las mujeres evidentemente poseen una opinión central a propósito del devenir nacional.

Finalmente, abordaremos el caso de los y las menores de edad. Aquí es necesario colocar ciertos puntos como base. Es que es complejo hablar de la historiografía de la infancia; como dice Aries, la categoría es relativamente reciente, entonces su historia está mediada también por este componente conceptual (1987). Los niños y niñas pueden ser, probablemente, los más invisibles dentro de esta muestra, básicamente porque no participan casi nunca de las arenas públicas o su opinión es siempre menoscabada dada su condición de incapaces. En su historia de la ciudad de Santiago, el ya mencionado Vicuña Mackenna se detiene en algunos apartados anecdóticos para hablarnos de la situación de los infantes, para ejemplificar el desarrollo urbano comenta lo evidente: las determinaciones que tomaban los padres para con sus hijos, desde el nombre hasta la ropa que utilizan. La vida de los niños gira en torno a decisiones que ellos no toman y, por lo tanto les ocurre algo similar a las mujeres dentro del siglo XIX: no tienen opinión. Esto genera todo un debate a propósito de lo que es aventurarse en la historia de la infancia; ¿son los niños y niñas realmente un objeto de estudio significativo? Claro, Vicuña Mackenna dentro de su revisión acerca de los temores infantiles, nos habla de los relatos de miedo que se les contaba a los niños en su tiempo (1869: 373-377). Ahora todo ello puede parecer inútil para la historiografía pero recordemos solo un punto: ¿Acaso nunca nos espantaron estos relatos a nosotros? ¿A ninguno le resultaba espeluznante o lúgubre? ¿O feliz y alucinante la fantasía? Todas estas cosas fueron importantes en algún momento determinado de nuestras vidas, pero claramente se van desdibujando en la medida que otros focos de interés 
comienzan a llamar nuestra atención. Existe entonces un reducto poco explotado acerca de la empatía que generan estas realidades y del cómo eso se aproxima a la historia de las mentalidades. Para el siglo XIX, en la conformación de Chile como nación, los niños son los grandes depositarios del modelo republicano que se pretendía implementar; por lo mismo, era indispensable su presencia en las aulas de clase y el objetivo de apropiación de una única historia de carácter nacional. El paulatino incremento de la educación formal buscaba entonces homogeneizar a los menores dentro de los postulados ya mencionados (Egaña y Monsalve, 2006: 136-137). Siendo este el caso, textos como los de Julio Bañados a propósito de Balmaceda tenían incluidos apartados que nos hablaban de la formación de los menores dentro de estos sistemas formativos nacionalistas (2005: 27). En la segunda mitad del siglo $X X$, los niños comenzaron a tomar otro tipo de valoración para la historiografía. No todos los niños se educaban o ni siquiera tenían la posibilidad de ser criados por sus propias familias y esto había que evidenciarlo de alguna manera. Trabajos icónicos son los de Salinas y Delgado a propósito del abandono de niños, un fenómeno no tan poco común en el Chile decimonónico, lo que repercutió en que el Estado tuvo que oír el clamor de los expósitos e intentar hacerse cargo de este problema con la construcción de casas de acogida (1990: 54). En otro plano, Salazar ha apostado por un intento novedoso de dar voz a los niños en un texto fundamental para entender nuestra realidad nacional acerca de la discriminación que se hacía entre los niños legítimos y los huachos; de esta manera, el autor intenta entonces acercarse a los más marginados dentro de los menores. La apuesta de Salazar es una de las más rupturistas en este sentido, se aproxima a la teoría de las emociones y de lo sensible para hacer comprender que el mundo de los infantes está rodeado por dichos elementos, por lo mismo, buscando las escasas fuentes desde el siglo XIX se concentra en la valoración desde el Estado y desde los mismos niños a propósito de lo que significaba la carencia de los padres o, lo que es lo mismo, ser un huacho (Salazar, 2006: 148). Pero si hay alguien que ha hecho de la infancia su especialidad ese es Jorge Rojas. Desde múltiples frentes, pero particularmente haciéndose cargo del fenómeno del trabajo infantil, Rojas se adentra en los postulados que comprende la materialización de grupos de niños con determinados rasgos de acción a nivel público, toda vez que estaban insertos en grupos laborales importantes como los que comprenden a los suplementeros (2006) y los cristaleros (1996), por nombrar parte de su obra. Es claro que el trabajo infantil es una constante hasta nuestros días, pero Rojas se atreve a presentarlo en una raigambre a la que no estamos habituados: niños con capacidad de determinación y con poder adquisitivo. Coloca su atención ahí en donde se trastoca el molde para hacer ver dentro de su historiografía que sí existe una voz de menores que ha sido históricamente ocultada, niños y niñas conscientes 
de su propia situación laboral y dispuestos a organizarse para denunciar lo que les parecía injusto.

Concluimos entonces esta revisión con una pregunta y una respuesta tentativa: ¿responden estos intentos de historia a la reivindicación efectiva de estos sujetos? A la luz de lo expuesto, queda medianamente entendido que, dentro de la historiografía, se ha intentado entonces colocar en el centro de la atención a dichos sujetos históricamente acallados; el cómo y el porqué ha estado condicionado a las fuentes y el carácter que sus autores han querido presentar en torno a sus sujetos de estudio, pero el solo hecho de haber puesto el foco en ellos y presentar su potencial, los faculta para llamar nuestra atención. El caso de la historiografía chilena, en ese sentido, se suscribe a las invitaciones hechas desde la escuela de Annales y son entonces depositarias de este legado adaptado a nuestra realidad orgánica. Se condice entonces la rápida muestra con un inicio y un final: la misma historia ha menospreciado a algunos y potenciado a otros, pero a la luz de los sucesos del siglo XX y las nuevas ópticas de visión, los antiguos actores secundarios chilenos hoy han pasado a los puestos de atención y del mayor interés de la comunidad académica.

\section{El currículo de Historia, Geografía y Ciencias Sociales: Inclusión y/o exclusión de los invisibles}

Como hemos visto, la historiografía se ha hecho cargo de visibilizar a aquellos actores que tradicionalmente habían sido marginados por la corriente tradicional. A pesar de este desarrollo, la historia enseñada y aprendida en nuestras escuelas ha mantenido en un silencio relativo a las mujeres, pobres, niñas, niños, jóvenes, indígenas, minorías sexuales, gitanos e inmigrantes, entre otros. Esta situación choca con la realidad, ya que los estudiantes forman parte de algunos de estos grupos y conviven cotidianamente con personas de algunos de ellos. La inmensa mayoría difícilmente tienen cerca a un político o a un héroe como los que aparecen en los textos escolares. La historia escolar, en general, sigue manteniendo la idea de que sus protagonistas son una minoría fundamentalmente de hombres blancos. Los contenidos que todos debemos conocer, son las hazañas de este grupúsculo.

El enfoque que busca privilegiar la enseñanza de los "grandes hombres", de los hacedores de la patria, en detrimento de los demás actores sociales, se ha visto favorecido en los últimos años tanto por las políticas del Estado en materia de educación, como por los medios de comunicación. A manera de ejemplo, podemos señalar que en medio de los actos simbólicos conmemorativos del Bicentenario, por la televisión abierta chilena fueron exhibidas una serie de programas ("Héroes", "Epopeya" y "Algo habrán hecho por la Historia de Chile") que perseguían construir una memoria colectiva sobre dos hitos considerados como fundadores de la identidad nacional chilena: 
principalmente, el proceso de independencia (1810-1818) y la guerra del Pacífico (1879-1883). El tercer programa trató de mostrar una visión cronológica de la historia del Chile republicano, siempre poniendo su acento en asuntos políticos y, por lo tanto, en personalidades destacadas en ese plano. Si bien en estos programas aparecían personas que podríamos denominar, utilizando el concepto de Hobsbawm, como "gente poco corriente" (Hobsbawm, 1999), sus roles no eran más que anecdóticos y supeditados al protagonismo de los ya mencionados grandes hombres.

Este es el panorama que encontramos en Chile con respecto a lo que se considera digno de preservar como parte de la memoria nacional. Al mantener en la invisibilidad a los otros actores, la historia escolar esconde una realidad multiétnica, regional y social con la que cada día se encuentran los maestros cuando ingresan a sus aulas de historia y ciencias sociales. Como profesores, al mostrar solamente una parte de la historia, provocamos una serie de consecuencias negativas en los y las estudiantes, entre ellas podemos destacar: una sensación generalizada en donde sólo las acciones de miembros dentro de una elite reducida pueden tener algún tipo de impacto público, también se separa a los otros miembros de la comunidad, excluyéndolos de todo poder y separándoles de la construcción del mundo en que nos desenvolvemos todos. Citando a Giroux, quitamos así la "(...) la posibilidad de que los seres humanos puedan constituir su propia realidad y alterarla y cambiarla frente a la dominación" (Giroux, 2003: 37). Y para cerrar, desestimamos la idea de formar individuos con herramientas críticas para interpretar su presente, de lo que se desprende una de las utilidades prácticas del conocimiento histórico.

Como ha señalado Pagès (Pagès, 2003; 2011 a y b) la incorporación de la enseñanza de la Historia y las Ciencias Sociales en el currículo escolar durante el siglo XIX y principios del siglo XX tuvo como uno de sus principales objetivos "(...) formar un determinado modelo de persona en consonancia con los valores dominantes (...)" (PAGÈS, 2011a: p. 17). Estos valores han estado relacionados principalmente con el nacionalismo imperante. Por medio de la promoción de ello se perseguía la consolidación y legitimación de las nuevas repúblicas en el caso de América, o de los nuevos Estados burgueses en Europa, y el desarrollo de un sentimiento de pertenencia a la colectividad, precisamente, la nación. A través de la enseñanza de la historia, niños, niñas y jóvenes eran socializados y conducidos a alcanzar todos esos atributos que debía poseer un "hombre útil" (De Olivera y Stephanou, 2013: 317) o un buen futuro ciudadano: amantes de la patria, obedientes a las autoridades, trabajadores, limpios, dispuestos a defender con la vida el territorio, obedecer a la ley, entre otros. Queda en evidencia que la inclusión en la escuela de la historia persiguió desarrollar sentimientos románticos-societales, en vez de centrarse en la promoción 
de los ideales ilustrados-disciplinares. Según Carretero y Kriger esto fue el resultado de la "(...) necesidad del Estado de inventar la nación" (2012: 70). Para Rosa (2004), la historia escolar se encuentra mediada por una serie de factores que hacen que ella se transforme en el espacio ideal para establecer memorias hegemónicas que dejan a un lado las experiencias de los colectivos. Haciendo referencia a los textos de estudio, el autor expresa que en ellos es evidente el componente ideológico que se pretende socializar al interior de las escuelas.

Durante los siglos XIX y gran parte del XX, el aterrizaje de la historia dentro de la escolaridad desde los Estados buscaba formar patriotas acérrimos. Esto se explica en gran medida por las características belicistas de dichas etapas. Para lograr una adhesión de parte de la población, a través de la historia se construyó un relato que mostraba una visión bastante estereotipada acerca de otros. A partir de la caída del muro de Berlín, empiezan a tomar distancia la historia como disciplina y la historia escolar:

"La Historia como disciplina comenzó a cuestionarse sus métodos y su objeto, tendiendo de modo general a relativizar la "Historias Únicas", dando lugar a diversas historias y a nuevos sujetos históricos, rompiendo con la concepción lineal regida por leyes inapelables (...) le permitieron incorporar el estudio de las identidades en términos culturales" (Carretero y Kriger, 2004: 85).

El divorcio entre la historia académica y el Estado permitió que la primera tomara posturas multiculturales y globales que dejaron a un lado las visiones nacionalistas. Este nuevo enfoque de la historia no hizo más que recoger las transformaciones que se vivieron en el mundo en las últimas décadas del siglo $X X$, y que cada vez con más fuerza comenzaron a sembrar la idea de que el mundo era mucho más amplio para ser estudiado. Para Carretero y Kriger la historia escolar no siguió este mismo camino. Se experimentaron en todas partes del mundo diversas reformas, pero lo que primó fue la resistencia al cambio. La persistencia de la tradición se hace evidente cuando aún se sigue enseñando la historia escolar a través de personajes tradicionales, principalmente héroes que son moldeados para parecer figuras centrales de los movimientos sociales. La persistencia de una mirada tradicional en la enseñanza de la historia escolar permite que las nuevas generaciones reproduzcan el modelo y se transformen en agentes pasivos. Las razones de esto son múltiples pero, a modo de ejemplo, podemos señalar que esta mirada de la historia les impide sentirse parte de ella, ya que no se presenta a sujetos con los cuales ellos puedan identificarse. Una historia centrada en héroes, santos, reyes, presidentes, etc., que no recoge las experiencias de vida de la gente corriente, impide evidenciar a las nuevas generaciones que ellos y ellas también son actores de la historia y, como tales, constructores del futuro. Al mismo tiempo, este tipo de historia no contribuye a que se puedan cuestionar las decisiones estatales en el pasado, puesto que 
tampoco son tratados mayormente los episodios conflictivos. Mucho menos se muestra al presente como un constructo del pasado o al futuro como algo plausible de ser conducido por todos y todas. Este panorama deja en evidencia la necesidad de repensar la enseñanza de la historia escolar, para que efectivamente contribuya a la formación de la ciudadanía del siglo XXI, una ciudadanía sustentada en el desarrollo del pensamiento social y la conciencia histórica. Rosa postula que promover la ciudadanía a través de las aulas de historia tendría que llevarnos necesariamente a pensar qué historia queremos enseñar, la historia de quién queremos enseñar, y para qué la queremos enseñar:

“Estas preguntas, por un lado, nos ponen de manifiesto el carácter necesariamente ideológico y político de la propia historia (...). Nos hacen situarnos en un escenario de transformación de las identidades nacionales en medio de las transformaciones demográficas, sociales, económicas y políticas en las que estamos inmersos. Tal vez la historia a enseñar no es una basada en relatos de acontecimientos protagonizados por unos personajes con los que nosotros hoy difícilmente podemos identificarnos, particularmente cuando estamos abocados a la transformación de nuestro propio ser colectivo (...)" (Rosa, 2004: 65).

Para Pagès (2003), la historia escolar se encuentra en un estado de crisis, debido fundamentalmente a que lo que se promueve en las aulas de historia y ciencias sociales es un tipo de conocimiento que se encuentra totalmente desvinculado de la realidad de niños, niñas y jóvenes. La historia aprendida en las escuelas no ayuda a los estudiantes a situarse en el mundo, no les permite entenderlo ni interpretarlo, tampoco les ayuda a hacerse con las herramientas para formarse como ciudadanos críticos y participativos, construir su propia identidad y/o la identidad colectiva (entendida esta en un sentido mucho más amplio que la mera identidad nacional). Un sistema de enseñanza de historia centrado en los grandes personajes políticos sumada a un modelo en el que prevalece la clase magistral, la utilización del libro de texto, y la presencia de estudiantes pasivos que sólo escuchan, ha dado como resultado que las nuevas generaciones no le asignen al aprendizaje de la historia ningún potencial ciudadano y, es más, que se muestren indiferentes ante la necesidad de participar en la construcción de la democracia y del futuro. Pagès explica que para poder hacer frente a esta situación de indiferencia juvenil es necesario utilizar nuevos métodos en la enseñanza de la historia; problematizar la historia escolar; evitar enfoques nacionales demasiado centralistas; y "Conceder mucho más protagonismo a los hombres y a las mujeres que a los territorios" (Pagès, 2011b: 20). Enseñando la historia escolar desde esta mirada, los estudiantes podrán reconocer en ella una disciplina que les permita entender su presente, situarse en este, y comprometerse en la construcción del futuro. 


\section{La aparición de los marginados en el currículo de Historia, Geografía y Ciencias Sociales de Educación Primaria en Chile}

Tomando en cuenta la propuesta conceptual que hemos expuesto es que decidimos hacer un análisis de los materiales curriculares que actualmente dirigen la enseñanza de la historia en los primeros cursos de educación primaria (de $1^{\circ}-4^{\circ}$ básico). Por esto, nos focalizamos en analizar las Bases Curriculares (2009) y los Programas de Estudio (2011), y en los textos de estudio entregados por el Ministerio de Educación en colegios públicos y particulares subvencionados ( $1^{\circ}$ básico Santillana; $2^{\circ}$ básico Santillana; $3^{\circ}$ básico Santillana; $4^{\circ}$ básico Norma). Acudimos a ellos preguntándonos si en este tipo de material pedagógico aparecen sujetos como nativos, mujeres, niños y niñas. Y, si es que están presentes, ¿cómo son expuestos?, ¿qué objetivos se persiguen con su aparición?

Debemos señalar que luego de revisar los materiales del primer ciclo de enseñanza básica, logramos reconocer una diferencia importante con respecto a los materiales de enseñanza media. Es posible observar en los cursos revisados una mayor referencia a dos de los colectivos que hemos asumido. Con respecto a los niños y las niñas, debemos señalar que en la presentación del subsector, frecuentemente se hace referencia a ellos en su calidad de estudiantes que deben apropiarse de los objetivos de aprendizaje que se abordarán durante el año escolar; a manera de ejemplo, se expresa a los profesores que al enseñar Historia, Geografía y Ciencias Sociales:

"El trabajo conjunto de estas disciplinas permite al alumno desarrollar conocimientos, habilidades y actitudes necesarias para comprender la compleja realidad contemporánea y su devenir histórico, para desenvolverse como un ciudadano capaz de actuar crítica y responsablemente en su sociedad, y para enfrentar los desafíos del mundo globalizado" (MINEDUC, 2011: 30).

Frecuentemente se hace referencia a niños y niñas en su calidad de estudiantes. Se invita a los docentes a ponerlos en el centro del proceso de enseñanza-aprendizaje, y a generar en ellos habilidades y actitudes que les permitan desarrollarse en el contexto en el cual se encuentran insertos. Estableciendo un vínculo entre niños y niñas y el sector de Historia, Geografía y Ciencias Sociales, se expresa que uno de los objetivos centrales de la presencia de esta asignatura en el currículo es contribuir a que los menores construyan su identidad y los lazos de pertenencia al contexto socio-cultural en el cual se encuentran insertos, citamos: 
"Saber quién es, conocer su comunidad y consolidar los lazos con ella son elementos fundamentales para el desarrollo integral de un niño. Ahí radica la base que permite a los alumnos comprender su cultura, apropiarse de ella y participar en su construcción" (MINEDUC, 2011, p. 30).

De esta manera, se expresa como una meta la construcción de niños-niñas como sujetos ciudadanos que conocen su contexto, las raíces históricas del mismo y que, a la vez, se involucren en la construcción del futuro.

Cuando nos focalizamos en los objetivos de aprendizaje que se encuentran relacionados con los conceptos de niños o niñas vemos importantes diferencias, dependiendo del curso en el cual nos estemos focalizando. En el siguiente cuadro podemos observar los objetivos que se relacionan con estos actores.

Cuadro 1: Presencia de niños y niñas en objetivos de aprendizaje de sector de Historia, Geografía y Ciencias Sociales ( $1^{\circ}-4^{\circ}$ básico)

\begin{tabular}{|c|c|c|}
\hline Nivel & Unidad & Objetivo de aprendizaje \\
\hline $1^{\circ}$ & 1 & $\begin{array}{l}\text { "Secuenciar acontecimientos y actividades de la vida cotidiana, } \\
\text { personal y familiar, utilizando categorías relativas de ubicación } \\
\text { temporal..." (OA 2) } \\
\text { "Registrar y comunicar información sobre elementos que forman } \\
\text { parte de su identidad personal (nombre, fecha de nacimiento, } \\
\text { lugar de procedencia, ascendencias, gustos, intereses, amigos y } \\
\text { otros) para reconocer sus características individuales" (OA 3) }\end{array}$ \\
\hline $1^{\circ}$ & 2 & $\begin{array}{l}\text { "Obtener y comunicar aspectos de la historia de su familia y } \\
\text { sus características, como costumbres, tradiciones, ritos, fiestas, } \\
\text { recuerdos y roles que desempeñan los distintos miembros de su } \\
\text { grupo familiar, mediante la formulación de preguntas a adultos } \\
\text { de su entorno cercano" (OA 4) }\end{array}$ \\
\hline $2^{\circ}$ & $x$ & $x$ \\
\hline $3^{\circ}$ & 2 & $\begin{array}{l}\text { Comparar modos de vida de la Antigüedad con el propio, } \\
\text { considerando costumbres, trabajos y oficios, creencias, } \\
\text { vestimentas y características de las ciudades, entre otros. (OA 4) }\end{array}$ \\
\hline $3^{\circ}$ & 4 & $\begin{array}{l}\text { Reconocer que los niños tienen derechos que les permiten recibir } \\
\text { un cuidado especial por parte de la sociedad con el fin de que } \\
\text { puedan aprender, crecer y desarrollarse, y dar ejemplos de cómo } \\
\text { la sociedad les garantiza estos derechos. (OA 14) }\end{array}$ \\
\hline
\end{tabular}

Fuente: Elaboración propia a partir de la revisión de programas de estudio de Historia, Geografía y Ciencias Sociales, MINEDUC, 2011.

Como podemos ver, es en primero básico donde encontramos una mayor cercanía entre las temáticas y objetivos a abordar y las experiencias de niños y niñas. Tanto en el programa de estudio como en el texto escolar, el principal 
protagonista es el niño o la niña (estudiante). A él o ella es a quien se invita a, desde su propia experiencia, apropiarse de ciertas habilidades de temporalización, de reconstrucción de su propio pasado y el de su familia, y a reconocer el rol que tiene en las distintas esferas en las que se desenvuelve cotidianamente. Consideramos que esta propuesta obedece, como ha señalado Carretero (2002) a la necesidad de desarrollar en ellos la comprensión del tiempo personal y físico.

Luego de la participación de los niños en las programaciones de primero básico, su actuación en el devenir histórico se diluye. Sólo aparecen de manera anecdótica para graficar la vida cotidiana en el mundo griego, romano, azteca, maya e inca. Su presencia no se vislumbra a partir de las programaciones, sino de las actividades propuestas en los textos de estudio. A manera de ejemplo, en la unidad $n^{\circ} 3$ de tercero básico (Los griegos de la antigüedad) se hace referencia a ellos al hablar de las características de las vestimentas:

"Los niños y las niñas de Grecia se vestían con las siguientes prendas: quitón, himmatión y sándalon" (Texto de estudio Historia, Geografía y Ciencias Sociales Tercero Básico. 2014. Editorial Santillana: 114).

En el curso cuarto básico ocurre algo similar, su presencia se visibiliza sólo a partir de un objetivo de aprendizaje localizado en la primera unidad y de algunas actividades presentes en el texto de estudio. Estos momentos en los que se les visibiliza son muy marginales, y están representados en situaciones que se presentan como anecdóticas. A manera de ejemplo, en la primera unidad del texto de estudio, cuando se hace referencia a los derechos de niños y niñas, se expresa:

"En el transcurso de la historia, los niños han tenido la posibilidad de disfrutar de juegos y juguetes que les han permitido relacionarse y conocer su entorno. Además, a través de estas manifestaciones, nosotros tenemos la posibilidad de conocer aspectos de la vida cotidiana de distintas sociedades" (Texto de estudio Historia, Geografía y Ciencias Sociales. 2014. Tercero Básico. Editorial Norma: 25).

El análisis que hemos desarrollado nos permite proponer que niños y niñas son partícipes de una historia más personal y cercana en primero básico, esto es lo que permite ver la historia desde su propia perspectiva. Esto se pierde posteriormente, y los niños y las niñas pasan a ser invisibles, o mostrárseles dentro del contexto de una historia de adultos, se les vincula con las mujeres, fundamentalmente por el rol que ellas ejercen al interior de los espacios cotidianos como madres.

Tomándonos de lo último señalado, podemos decir que a partir de nuestra revisión de los materiales curriculares de enseñanza básica hemos podido constatar que la presencia de las mujeres en estos es bastante marginal. 
En el caso de primero básico, su presencia se presenta vinculada a su rol de madre y, por lo tanto, como un actor relacionado con los menores, junto a actividades de aprendizaje que este debe desarrollar para apropiarse de ciertos elementos de investigación y comunicación. A manera de ejemplo, en la segunda unidad encontramos el siguiente objetivo que las visibiliza:

"Obtener y comunicar aspectos de la historia de su familia y sus características, como costumbres, tradiciones, ritos, fiestas, recuerdos y roles que desempeñan los distintos miembros de su grupo familiar, mediante la formulación de preguntas a adultos de su entorno cercano" (Unidad 2, O A 4, Programa de estudio Historia, Geografía y Ciencias Sociales, Primero Básico).

La segunda vez que aparecen las mujeres en las programaciones de primero básico, es relacionándolas con personajes que han generado algún tipo de aporte a la sociedad chilena, por lo que no son las mujeres comunes, sino que son aquellas que comparten un sitial de importancia dentro de un espacio que hasta hace poco era sólo destinado a los hombres:

"Conocer sobre la vida de hombres y mujeres que han contribuido a la sociedad chilena en diversos ámbitos (...)" (Unidad 3, OA 7).

En los otros niveles revisados, la mujer solamente aparece cuando se hace referencia a la vida cotidiana y a las actividades que en este espacio comparten con los hombres. Así, por ejemplo en tercero básico, cuando se revisan las civilizaciones griega y romana, se acude a ellas para expresar cómo era la vida de la gente común en el marco de estas culturas:

Unidad 3, OA 4: "Comparar modos de vida de la Antigüedad con el propio, considerando costumbres, trabajos y oficios, creencias, vestimentas y características de las ciudades, entre otros".

Indicador de evaluación: Dan ejemplos, apoyándose en imágenes y fuentes dadas, de las actividades que realizaban hombres, mujeres y niños en la antigua Roma (MINEDUC, 2011).

Al contrastar esta información con la presente en el texto de estudio, la referencia que se hace a las mujeres en el mundo romano es mínima:

"En las familias romanas el hombre más importante era el pater familia, quien mandaba y era dueño de los demás integrantes y de todas las propiedades, incluyendo los esclavos. La mater o madre de la familia organizaba el trabajo de los esclavos y bordaba. En algunas podía salir a comprar o acompañaba a su esposo a espectáculos" (Texto de estudios Historia, Geografía y Ciencias Sociales. Tercero Básico. Editorial Santillana: 170). 
Adaptando la propuesta conceptual de Marolla (2014) a la presencia y/o ausencia de mujeres en las programaciones y textos de estudio, podemos establecer que ellas pueden ser visibilizadas de la siguiente manera: 1) La historia sin mujeres, 2) La historia con algunas mujeres notables, 3) La contribución de las mujeres en la historia de los hombres, y 4) La historia desde la perspectiva de las mujeres. Las programaciones de $1^{\circ}$ a 4 básico muestran la presencia de la mujer de manera marginal, por lo que podríamos decir que se transita desde una historia que las excluye hacia una historia donde las féminas contribuyen en la historia de los hombres. La única excepción la encontramos en primero básico, cuando se evidencia el rol de algunas mujeres notables, es decir, la contribución en la historia y cultura nacional de aquellas que escapan a los cánones tradicionales asignados a su condición de género.

Como lo han evidenciado las investigaciones de Pagès y Villalón (2015), la presencia del colectivo indígena tiene un importante espacio en las programaciones y los textos de estudio de enseñanza básica. Ambos se focalizaron en la revisión de los textos de estudio de segundo, quinto y sexto básico para ver la cantidad de lecciones que estaban dedicadas a ellos, y la manera en que se abordaba su historia. Las conclusiones a las que llegaron son bastante similares a las que nosotros hemos podido establecer a partir de la revisión de programaciones y textos de estudio. En segundo básico, de 16 objetivos de aprendizaje destinados a ser abordados en el año escolar, 6 están enfocados en los pueblos originarios. Como podemos observar en el siguiente gráfico, de los colectivos analizados en este artículo, son quienes tienen más presencia en las lecciones de los textos de estudio:

Gráfico 1. Presencia de invisibles en textos de estudio

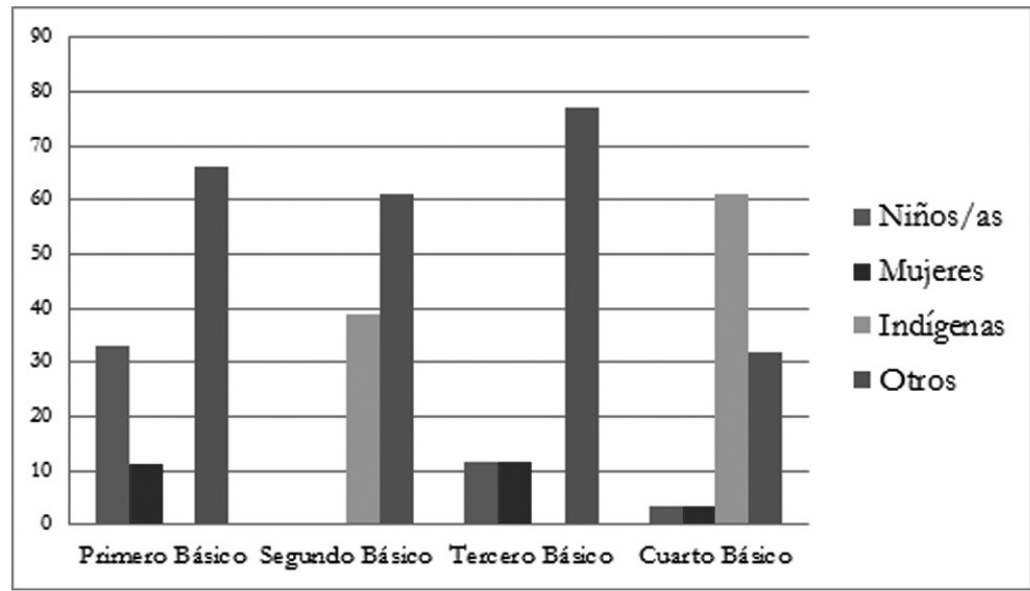

Fuente: Elaboración propia a partir del análisis de unidades de textos de estudio entregados por el MINEDUC el año 2016. 
El gráfico es claro al mostrarnos que el colectivo de los indígenas es el que tiene un espacio más importante en las programaciones de $1^{\circ}$ a $4^{\circ}$ básico. $\mathrm{Si}$ los contrastamos con mujeres y niños y niñas hay una presencia marcada en dos niveles (segundo y cuarto básico). Según nuestro análisis, la problemática no radica en este colectivo en su ausencia, sino que más bien, en cómo se presentan los contenidos que están asociados a ellos. La aparición de estos actores se encuentra anclada en un pasado remoto. Para comenzar, se les denomina como pueblos originarios, los temas sólo hacen referencia a un pasado que, por lo demás, no se encuentra temporalizado. En los momentos en los cuales se les hace dialogar con el presente, es fundamentalmente para evidenciar cuál es el legado cultural que nos han dejado. La visión acerca de su herencia es bastante estrecha, puesto que se focaliza preferentemente en elementos folclóricos. A partir de su legado se genera la sensación de que lo único que hemos heredado de este colectivo son algunas palabras y comidas.

"Describir los modos de vida de algunos pueblos originarios de Chile en el periodo precolombino, incluyendo ubicación geográfica, medio natural en que habitaban, vida nómada o sedentaria, roles de hombres y mujeres, herramientas y tecnología, principales actividades, vivienda, costumbres, idioma, creencias, alimentación y fiestas, entre otros" (OA 1).

No se hace referencia a la situación conflictiva que se fundó y mantiene hasta la actualidad entre el hombre blanco y el indígena. Menos aún se evidencian las luchas que mantienen, por ejemplo con el Estado chileno, para poder preservar sus tradiciones y su cultura. A manera de ejemplo, cuando se aborda el mestizaje, es de una manera muy simplificada, como el establecimiento de una realidad que fue aceptada por todos los actores participantes sin resistencias. Las imágenes que grafican esto, además proyectan un fuerte sexismo (es el hombre blanco quien establece una relación con la mujer indígena) ${ }^{3}$. En cuarto básico, cuando se abordan las Grandes Civilizaciones, ocurre exactamente lo mismo al tratar la historia luego de la conquista, lo que se manifiesta es la vida de las elites de estos grupos.

\section{Conclusiones}

Volviendo a las preguntas iniciales de esta investigación, podemos afirmar que efectivamente mujeres, niños, niñas e indígenas aparecen en las programaciones y textos de estudio de los primeros cursos de enseñanza básica, así como también de forma transversal en la historiografía chilena. La presencia de estos colectivos es totalmente variada, siendo los indígenas

Ver texto de estudio segundo básico editorial Santillana, p. 124-125. 
quienes logran una mayor presencia. Mujeres son quienes menos aparecen. Mientras que niños y niñas tienen una fuerte presencia en primero básico.

Respondiendo al cómo son presentados los colectivos señalados y bajo qué objetivos, es posible acotar de forma parcelada que la presencia de los niños y las niñas obedece fundamentalmente a generar una mayor identificación y motivación con la asignatura. Podríamos agregar, además, que su inclusión obedece a una didáctica que persigue que ellos y ellas se apropien del tiempo personal y físico. Queda como una tarea pendiente la inclusión de las mujeres en el currículo de enseñanza básica. Su presencia es tan marginal que establece la necesidad de repensar los contenidos que se enseñan en estos niveles, para que su exposición sea más permanente. Finalmente, la aparición de los indígenas es más compleja. De hecho a partir de esta revisión, más que respuestas emergieron nuevas preguntas: ¿Se busca a través de su inclusión provocar un sentido de pertenencia? ¿Se les quiere mostrar que su historia también se enseña en las escuelas? ¿Se busca que los estudiantes valoren la conformación de una sociedad mestiza? ¿Se pretende validar sólo los aportes folclóricos del mundo indígena? Consideramos que a partir de las propuestas revisadas, se hace necesario repensar qué historia del mundo nativo queremos enseñar, si una que efectivamente evidencia las dificultades y desigualdades que este colectivo hasta el día de hoy debe enfrentar, o más bien una historia que se aparta del presente para evitar el abordaje del conflicto. En los planos propiamente disciplinares se puede destacar que la aparición de dichos componentes sociales ha intentado ser utilizada desde una valoración dispar, la cual buscaría resaltar aspectos negativos y/o positivos de los que se entienden como los marginales en este análisis. Los actores que se presentaron de manera anecdótica en el pasado de la historiografía, hoy han pasado a ocupar un lugar protagónico, depositario de una mirada más integrativa y que busca la reivindicación. A pesar de ello, si bien es cierto la comunidad académica ha estado más propensa a incluir a mujeres, nativos, niños y niñas, la premisa reivindicativa no ha logrado permear del todo al currículo de enseñanza básica en el ciclo seleccionado, lo que constituye una tarea pendiente hacia la inclusión, sin desmerecer los intentos que se han presentado en este trabajo.

\section{Referencias bibliográficas}

\section{Fuentes Primarias}

a) Documentales

MINEDUC (2011). Programa de estudio Historia, Geografía y Ciencias Sociales, primero, segundo, tercero y cuarto básico. Santiago: Ministerio de Educación. 


\section{Fuentes Secundarias}

\section{a) Artículos}

Carretero, M. y Kriger, M. (2004). " ¿Forjar patriotas o educar cosmopolitas? El pasado y el presente de la historia escolar en un mundo global" en CARRETERO, M.; VOSS J. (Coords.). Aprender y pensar la historia. Buenos Aires: Amorrortu ediciones, pp. 71-98.

De Olivera y Stephanou (2013). "Memorias de lecturas de infancia: la Série Fontes de Brasil". En Sosenski y Jackson, E., Nuevas miradas a la historia de la infancia en Latinoamérica. Consultado en http://www.historicas.unam.mx/publicaciones/ publicadigital/libros/miradas/miradas.html, pp. 34-45.

Egaña; M. L. y Monsalve, M. (2006). "Civilizar y moralizar en la escuela primaria popular" en Sagredo, R. y Gazmuri, C. (Eds.). Historia de la Vida Privada en Chile. Tomo II. Santiago: Editorial Taurus, pp. 119-137.

Marolla, J. (2014a). " ¿Aún son invisibles las mujeres? Análisis de la presencia de la historia de las mujeres en los libros de texto de secundaria chilenos" en Pagès, J.; Santisteban, A. (Eds.). Una mirada al pasado y un proyecto de futuro. Investigación e innovación en didáctica de las ciencias sociales. Volumen I. Barcelona: AUPDCS/ Servei de Publicacions de la Universitat Autònoma de Barcelona, pp. 305-314.

Pagès, J. (2011a). "Educación, ciudadanía y enseñanza de la historia”, en Guimâraes Fonseca, S. y Gatti Júnior, D. Perspectivas do ensino de história: ensino, cidadania e consciencia histórica. Uberlandia: EDUFU/PAPEMING, pp. 17-31.

Pagès, J. (2011b). "La educación para la ciudadanía y la enseñanza de la historia: cuando el futuro es la finalidad de la enseñanza del pasado", en Ávila R. M. López, R. y Fernández, E. (Eds.). Las competencias profesionales para la enseñanza-aprendizaje de las Ciencias Sociales ante el reto europeo y la globalización. Bilbao: Asociación Universitaria del Profesorado de Didáctica de las Ciencias Sociales, pp. 205-215.

Pagès, J. (2003). "Ciudadanía y enseñanza de la historia" en Reseña de la enseñanza de la historia. Argentina: Revista de la APEHUN, Asociación de Profesores de Enseñanza de la Historia de Universidades Nacionales, pp. 11-42.

Piper, I. (2000). "Memorias del pasado para el futuro" en Garcés, M., Milos, P., Olguín, M., Pinto, J., Rojas, M. T. y Urrutia, M. (Comps.). Memoria para un nuevo siglo. Chile, miradas a la segunda mitad del siglo XX. Santiago: LOM Ediciones, pp. 91-98.

Rosa, A. (2004). "Memoria, historia e identidad. Una reflexión sobre el papel de la enseñanza de la historia en el desarrollo de la ciudadanía" en Carretero y Voss (Eds.). Aprender y pensar la historia. Buenos Aires: Amorrortu ediciones, pp. 47-69. 
Salinas, R. y Delgado, M. (1990). "Los hijos del vicio y del pecado. La mortalidad infantil de los niños abandonados (1750 - 1930)" en Proposiciones. Volumen 19. Santiago: Editorial SUR, pp. 44-54.

Villalón, G. y Pagès, J. (2015). "La representación de los y las indígenas en la enseñanza de la historia en la educación básica chilena. El caso de los textos de estudio de historia de Chile", en Diálogo Andino, n 47. Arica: UTA, pp. 27-36.

\section{b) Libros}

Amunátegui, D. (1909). Las encomiendas de Indígenas de Chile. Santiago: Memoria Histórica. Universidad de Chile.

Apple, M. (1986). Ideología y currículo. Madrid: Editorial Akal.

Ariès, P. (1987). El niño y la vida familiar en el Antiguo Régimen. Madrid: Editorial Taurus.

Bañados, J. (2005). Balmaceda, su gobierno y la revolución de 1891. Tomo I. Santiago: Ediciones Centro de Estudios Bicentenario.

Barros Arana, D. (2000). Historia General de Chile. Tomo I. Santiago: Editorial Universitaria.

Bengoa, J. (2004). Historia olvidada. Historia de los pueblos indígenas de Chile. Santiago: Publicaciones del Bicentenario.

Burke, P. (1999). La Revolución Historiográfica Francesa. Barcelona: Editorial Gedisa.

Carretero, M. (2002). Construir y enseñar las ciencias sociales y la historia. Madrid: Antonio Machado libros.

Carretero, M., Rosa, A. y González, M. (2006). Enseñanza de la historia y memoria colectiva. Buenos Aires: Paidós.

Cot, N. y Morán, M. (2015). Historia, geografía y ciencias sociales, texto del estudiante cuarto básico. Santiago. Norma.

Fukuyama, F. (1992). El fin de la Historia y el Último Hombre. Buenos Aires: Editorial Planeta.

Giroux, H. (2003). Pedagogía y política de la esperanza: teoría, cultura y enseñanza. Buenos Aires: Amorrortu Ediciones.

Gumucio, A., Muñoz, P., y Ponti, M. (2014). Historia, geografía y ciencias sociales, texto del estudiante tercero básico. Santiago: Santillana.

Hobsbawm, E. (1968). Rebeldes primitivos, estudio sobre las formas arcaicas de los movimientos sociales en los siglos XIX y XX. Barcelona: Ediciones Ariel.

Hobsbawm, E. (1998). Gente poco corriente, resistencia, rebelión y jazz. Barcelona: Editorial Crítica. 
Illanes, M. A. (2006). Cuerpo y sangre de la política: la construcción histórica de las visitadoras sociales, Chile, 1887-1940. Santiago: LOM Ediciones.

Koselleck, R. (1993). Futuro Pasado. Para una semántica de los tiempos históricos. Barcelona: Editorial Paidós.

Mansoulet, J. (1893). Guía Crónica de la Frontera Araucana de Chile 1892-93. Santiago: Imprenta y Cuadernos Barcelona.

Millalén, J., Marimán, P., Levil, R., y Caniuqueo, S. (2006). j... Escucha, Winka...! Cuatro Ensayos de Historia Nacional Mapuche y un Epílogo sobre el Futuro. Santiago: LOM Ediciones.

Pinto, J. (2003). La Formación del Estado y la Nación y el Pueblo Mapuche. De la Inclusión a la Exclusión. Santiago: Dirección de Bibliotecas, Archivos y Museos.

Rojas, J. (1996). Los niños cristaleros: trabajo infantil en la industria. Chile, 18801950. Santiago: Dirección de Bibliotecas, Archivos y Museos.

Rojas, J. (2006). Los suplementeros: niños y venta de diarios. Chile, 1880-1953. Santiago: Ariadna Ediciones.

Salazar, G. (2007). Ser Niño Huacho en Chile (siglo XIX). Santiago: LOM Ediciones. Suárez, J. F. (1909). Rasgos biográficos de mujeres célebres de América. París México: Librería de la Vda de Cj. Bouret.

Vásquez, D. (2014). Historia, geografía y ciencias sociales, texto del estudiante primero básico. Santiago: Santillana.

Vásquez, D. (2014). Historia, geografía y ciencias sociales, texto del estudiante segundo básico. Santiago: Santillana.

Veneros, D. (Ed). (1997). Perfiles Revelados. Historia de las Mujeres en Chile, siglo XVII - XX. Santiago: Universidad de Santiago de Chile.

Vicuña Mackenna, B. (1869). Historia crítica y social de la ciudad de Santiago desde su fundación hasta nuestros días (1541 - 1868). Valparaíso: Imprenta del Mercurio.

Vicuña Mackenna, B. (1887). Los Lisperguer y la Quintrala. Valparaíso: Imprenta del Mercurio.

Zárate. M. S. (2007). Dar a Luz en Chile, siglo XIX. De la "ciencia de la hembra" a la ciencia obstetricia. Santiago: Dirección Nacional de Bibliotecas, Archivos y Museos. 